\title{
Corrigendum: Microscopic origins of the large piezoelectricity of leadfree $(\mathrm{Ba}, \mathrm{Ca})(\mathrm{Zr}, \mathrm{Ti}) \mathrm{O}_{3}$
}

Yousra Nahas, Alireza Akbarzadeh, Sergei Prokhorenko, Sergey Prosandeev, Raymond Walter, Igor Kornev, Jorge Íñiguez \& L. Bellaiche

Nature Communications 8:15944 doi:10.1038/ncomms15944 (2017); Published 20 Jun 2017; Updated 25 Oct 2017

The affiliation details for Sergei Prokhorenko are incorrect in this Article. A second affiliation should have been included as given below:

Theoretical Materials Physics, Q-MAT CESAM, Université de Liège, B-4000 Sart Tilman, Belgium.

Also, the financial support for this Article was not fully acknowledged. The Acknowledgements should have included the following: Sergei Prokhorenko thank the University of Liege and the EU in the context of the FP7-PEOPLE-COFUND-BeIPDproject.

(c) Open Access This article is licensed under a Creative Commons Attribution 4.0 International License, which permits use, sharing, adaptation, distribution and reproduction in any medium or format, as long as you give appropriate credit to the original author(s) and the source, provide a link to the Creative Commons license, and indicate if changes were made. The images or other third party material in this article are included in the article's Creative Commons license, unless indicated otherwise in a credit line to the material. If material is not included in the article's Creative Commons license and your intended use is not permitted by statutory regulation or exceeds the permitted use, you will need to obtain permission directly from the copyright holder. To view a copy of this license, visit http://creativecommons.org/licenses/by/4.0/

(C) The Author(s) 2017 